\title{
Workplace Victimization in the Public Sector: Evidence on Negative Affectivity and Conflict Styles
}

\author{
Joko Suyono* \\ Faculty of Economics and Business, Universitas Sebelas Maret, Indonesia
}

\begin{abstract}
The purpose of the study is to analyze negative affectivity and conflict styles as potential causes of workplace victimization. A sample survey of 100 respondents was conducted in the public sector in Indonesia. Multiple regression analysis was used in the study to test the hypothesis. Results suggested that there was a significant relationship between negative affectivity and perceived victimization. Furthermore, we found that conflict styles were related to perceived victimization. Obliging style and integrating style had a negative relationship with perceived victimization. Meanwhile, the dominating style was positively related to perceived victimization. This study investigated empirically workplace victimization in the public sector from the victims' perspective. Caution should be exercised in generalizing the results. Future studies can investigate both victims' and perpetrator's perspectives in the analysis of workplace victimization. Also, future research should pay attention to the extent to which certain types of leaders, organizational factors and person behaviors influence victimization. An understanding of individual determinants will help an organization to prevent victimization in the environment. Also, the organization should have a certain mechanism to protect employees from workplace victimization. To the extent of the author's knowledge, this research is one of the few studies that has been made from the victim's perspective of workplace victimization in the public sector in Indonesia.
\end{abstract}

Keywords: Negative Affectivity, Conflict Style, Victimization

\section{Introduction}

Deviance behaviors in the workplace have gained increasing attention in the scholarly, such as antisocial behaviors (Giacalone and Greenberg, 1997), aggressive actions, interpersonal conflict, and sabotage in the workplace (Fox et al., 2001). The negative behaviors may bring severe consequences for organizations and employees by influencing organization functions or threating employees, which in turn decreasing their performance.

Many studies have primarily focused on perpetrators and their behaviors that are intended to harm others (Baumeister et al., 1996; Felson, 1992; Glomb, 2002; Hepworth and Towler, 2004). In contrast, based on the victimology approach, it is important to take factors other than perpetrators into consideration to get full understanding about workplace victimization.

Aquino (1999) defined victimization as the individual's self-perception of having been exposed, either momentarily or repeatedly, to aggressive actions emanating from one or more other persons. Based on the Victim Precipitation Theory, some people have a high risk of being victims by conflicting with potential perpetrators (Tepper et al., 2006). In this case, individuals' characteristics can contribute to their victimization. One of the characteristics is negative affectivity.

Negative affectivity reflects dispositional tendency to experience high level of distressing emotions, like anger, hostility, sadness and fear (Tepper et al., 2006). People with high Negative

\footnotetext{
* Corresponding author at Jl. Ir Sutami No.36 A, Pucangsawit, Kec. Jebres, Kota Surakarta, Jawa Tengah 57126. Email: jokosu_jmfeuns@yahoo.co.id
} 
Affectivity tend to be victims by showing weaknesses to protect themselves from aggressive acts (Aquino, 1999). People with high-negative affectivity may become targets of victimization because of some reasons: (1) interpret a large proportion of their interaction with others as identity threats, (2) respond to these threats with hostility or aggression, and (3) provoke others to respond them in adverse ways (Burke et al., 1993).

Victimization may also be related to conflict style. Conflict occurs when an individual perceives his/her interest as being obstructed or negatively affected by another party. Conflict is generally defined as a disagreement concerning investment or ideas. As human being interacts in organizations, differing values and situations create tension. Conflict is thereby viewed as a situation in which two or more individuals operating within a unit appear to be incompatible (Lee, 2008). According to Aquino, K. (2000), the behaviors associated with the conflict style parallel those that have been shown to distinguish victims from non-victims. Employees who rely on styles more than others may unwittingly present themselves as potential targets of aggressive action.

This study applies a victimology approach by examining the relationship between negative affectivity and conflict styles (integrating, obliging and dominating). By anticipating the causes of victimization, the organization may prevent the conditions that lead to victimization, and employees may manage themselves to avoid being the targets of victimization as well.

\section{Related literature and hypothesis development}

Aquino (1999) defined victimization as an individual's perception of having been exposed, either momentarily or repeatedly, to the aggressive acts of one or more other persons. In other words, Hauge et al., (2007) labeled "workplace bullying", that bullying is not about the individual, isolated aggressive actions, but rather about behavior that is repeated and persistently directed at one or more individuals by an individual or by a group. Victimization can take in various forms, such as public humiliation, constant criticism of work, and reduction of the formal status of an employee (Wornham, 2003). In addition, Wornham (2003) identified six forms of bullying: organizational (related to the performance of an employee); social isolation, reference to the individual's private "sphere"; verbal aggression; physical aggression; and the use of rumor-spreading.

A victim, in the most general sense is anyone who experiences injury, loss, or misfortune as a result of some events or series of events (Aquino and Lamertz, 2004). Based on the victim precipitation model, victim types may contribute to some degree of victimization. To be considered a target of bullying, exposed individuals must find it difficult to defend themselves in the ongoing situation (Hauge et al., 2007). In addition, some people become targets of aggressive actions because they behave passively; others are chosen because they exhibit threatening, aggressive, or irritating behaviors (Aquino, 2000). Thus, a certain type of individual, either submissive or aggressive type, may become more frequent targets of victimization.

According to victim precipitation theory, some individuals could get a higher risk of being victims by provoking the hostility of potential perpetrators. In this situation, an individual may consciously or unconsciously produce certain acts, thus he or she may have been placed at risk of being victimized. This is related to Negative Affectivity. Negative Affectivity reflects a higher-order personality variable describing the extent to which an individual experiences, either in terms of frequency or intensity, high levels of distressing emotions such as anger, hostility, fear, and anxiety (Watson and Clark, 1984).

Tepper et al. (2006) identified two reasons why people with high negative affectivity tend to be the targets of perpetrators: (1) high negative affectivity persons present themselves as anxious, distressed, and dissatisfied, thus the perpetrators may see them as potential targets of aggressive actions; (2) because high negative affectivity persons frequently experience emotional distress, they may be more likely to violate rules of social interaction and have performance problems, which results in behaviors that others may perceive as annoying and disrespectful.

The characteristics of high negative affectivity provide a plausible link between negative affectivity and victimization. According to Burke et al. (1993), people with high negative affectivity tend to be potential victims because they: (1) interpret most of their interaction with other people as identity threats; (2) respond to these threats with hostility or aggression, and (3) provoke others to respond them in adverse ways. Based on the literature described above, we test the following hypothesis: 


\section{H1: Negative affectivity is positively related to perceived victimization.}

Burke et al. (1993) defined conflict as an interactive process manifested in incompatibility, disagreement, or dissonance within or between social entities (i.e., individual, group, organization, etc.). Calling conflict an interactive process does not preclude the possibilities of intraindividual conflict, for it is known that a person often interacts with himself. Obviously, one interacts with others. According to Burke et al., (1993) conflict occurs when: (1) A party is required to engage in an activity that is incongruent with his or her needs or interests; (2) A party holds behavioral preferences, the satisfaction of which is incompatible with another person's implementation of his or her preferences; (3) A party wants some mutually desirable resource that is in short supply, such that the wants of everyone may not be satisfied fully; (4) A party possesses attitudes, values, skills, and goals that are salient in directing his or her behavior but are perceived to be exclusive of the attitudes, values, skills and goals held by other(s); (5) Two parties have partially exclusive behavioral preferences regarding their joint actions; (6)Two parties are interdependent in the performance of functions or activities.

Based on Rahim's Conflict Styles Model, there are five styles of handling conflict: (1) Integrating (great concern for self and others) is associated with problem-solving. The use of this style involves openness, exchanging information, looking for alternatives, and examination of differences to reach an effective solution acceptable to both parties; (2) Obliging (low concern for self and high concern for others) is associated with attempting to play down the differences and emphasizing commonalities to satisfy the concern of the other party; (3) Dominating (high concern for self and low concern for others) has been identified with win-lose orientation or with forcing behavior to win one's position; (4) Avoiding (low concern for self and others) has been associated with withdrawal, buckpassing, or sidestepping situations; (5) Compromising (intermediate in concern for self and others) involves give-and-take whereby both parties give up something to make a mutually acceptable decision

According to Aquino, (2000), one prediction that can be derived from the conflict styles model is that an employee who routinely gives in to others' demands, or who tries to avoid conflict, may present him or herself as a submissive victim; that is someone who is perceived as weak, unassertive, and socially withdrawn. Furthermore, Aquino, K., (2000) stated that researchers have also identified a subset of victims who are highly aggressive and therefore elicit aggressive responses from others. In other words, because of their aggressive and provocative behaviors, they become vulnerable targets of victimization. Thus, we propose the hypotheses as followed:

\section{H2: Obliging style is positively related to perceived victimization}

H3: Dominating style is positively associated with perceived victimization

Drawing from the conflict styles model, it could be assumed that employees who exhibit integrating style may become the least likely target of victimization. They will not become the targets because they show their flexibility and concern for others' interests. Therefore, the following hypothesis is proposed:

\section{H4: Integrating style is negatively related to perceived victimization}

\section{Method}

One hundred employees (57 men and 43 women) of a municipal government in Indonesia voluntarily completed the survey. All participants were guaranteed confidentiality. The average age was 38 years; their tenure ranged from 3 years to 45 years, and $55 \%$ of participants were undergraduate degrees.

Negative affectivity reflected negative feelings experienced by an individual (such as fear, anger, and anxiety). To measure negative affectivity, ten items subscale ( $1=$ strongly disagree to $5=$ strongly agree) from Watson et al. (1988) was used. The coefficient alpha was 90.

Conflict style indicated the various style of behavior by which interpersonal conflict may be handled. Participants completed items from Rahim Organizational Conflict Inventory-IIII (ROCI-II) to assess conflict style ( $1=$ never to $5=$ always). The ROCI-II was designed to measure several dimensions 
of handling conflict, including integrating, obliging, and dominating. The coefficient alpha for Integrating was .876; Obliging was .804, and Dominating was 0.724 .

Fourteen items from Aquino's (1999) scale were operationalized. Respondents answered on a five-point Likert Scale (1=never to 5=Always). The questions asked respondents about their personal experiences of aggressive behaviors from co-workers. The coefficient alpha was .886 .

\section{Results and Discussion}

Correlation among variables is presented in Table 1. Negative affectivity is positively correlated with victimization $(\mathrm{r}=.620, p<.01)$; integrating Style is negatively correlated with victimization $(\mathrm{r}=$ $-.289, p<.01)$; obliging Style is negatively correlated with victimization $(\mathrm{r}=-.228, p<.05)$ and dominating Style is positively related to victimization $(\mathrm{r}=.233, p<.05)$.

Table 1. Correlation matrix

\begin{tabular}{llrrrrr}
\hline & \multicolumn{1}{c}{ AN } & \multicolumn{1}{c}{ INT } & \multicolumn{1}{c}{ OBL } & \multicolumn{1}{c}{ DOM } & \multicolumn{1}{c}{ VIC } \\
\hline AN & Pearson Correlation & 1 & -.172 & -.098 & .101 & $.620 * *$ \\
& Sig. (2-tailed) & & .087 & .333 & .319 & .000 \\
& $\mathrm{~N}$ & 100 & 100 & 100 & 100 & 100 \\
\hline INT & Pearson Correlation & -.172 & 1 & $.344 * *$ & .029 & $-.289 * *$ \\
& Sig. (2-tailed) & .087 & & .000 & .778 & .004 \\
& $\mathrm{~N}$ & 100 & 100 & 100 & 100 & 100 \\
\hline OBL & Pearson Correlation & -.098 & $.344 * *$ & 1 & .079 & $-.228^{*}$ \\
& Sig. (2-tailed) & .333 & .000 & & .433 & .022 \\
& $\mathrm{~N}$ & 100 & 100 & 100 & 100 & 100 \\
\hline DOM & Pearson Correlation & .101 & .029 & .079 & 1 & $.233^{*}$ \\
& Sig. (2-tailed) & .319 & .778 & .433 & & .020 \\
& $\mathrm{~N}$ & 100 & 100 & 100 & 100 & 100 \\
\hline VIC & Pearson Correlation & $.620 * *$ & $-.289 * *$ & $-.228 *$ & $.233 *$ & 1 \\
& Sig. (2-tailed) & .000 & .004 & .022 & .020 & \\
& $\mathrm{~N}$ & 100 & 100 & 100 & 100 & 100 \\
\hline
\end{tabular}

Note: **. Correlation is significant at the 0.01 level (2-tailed) *. Correlation is significant at the 0.05 level (2-tailed)

Table 2 presents the regression results using multiple regression analysis, regressing victimization on negative affectivity and conflict styles, which consist of integrating style, obliging style, and dominating style. Our results suggest a positive relationship between negative affectivity and perceived victimization $(\beta=.360, p<.05)$, supporting hypothesis 1 . In the relationship of conflict style to perceived victimization, the obliging style has a negative effect on perceived victimization $(\beta=-.076$, $p<.10$ ). Thus, this finding contrast with hypothesis 2 . The regression analysis also shows a positive association between dominating style and perceived victimization $(\beta=.102, p<.05)$, in line with hypothesis 3 . Furthermore, there is negative relationship between integrating style and perceived victimization $(\beta=-.110, p<0.10)$. Thus, hypothesis 4 was supported.

Table 2. Multiple Regression Analysis

\begin{tabular}{llrrrrl}
\hline \multirow{2}{*}{ Model } & \multicolumn{2}{c}{$\begin{array}{c}\text { Unstandardized } \\
\text { Coefficients }\end{array}$} & \multicolumn{2}{c}{$\begin{array}{c}\text { Standardized } \\
\text { Coefficients }\end{array}$} & \multirow{2}{*}{$\mathrm{t}$} & \multirow{2}{*}{ Sig. } \\
\cline { 3 - 5 } & & \multicolumn{1}{c}{ B } & Std. Error & Beta & & \\
\hline 1 & (Constant) & 1.078 & .296 & & 3.635 & .000 \\
& AN & .360 & .049 & .562 & 7.340 & $.000^{* *}$ \\
& INT & -.110 & .059 & -.150 & -1.866 & $.065^{*}$ \\
OBL & -.076 & .044 & -.137 & -1.708 & $.091^{*}$ \\
& DOM & .102 & .040 & .192 & 2.537 & $.013^{* *}$ \\
\hline
\end{tabular}

Note: Dependent Variable: VIC. ${ }^{*} \mathrm{p}<.10,{ }^{* *} \mathrm{p}<.05$ 
This study aims to examine the effects of negative affectivity and conflict styles on workplace victimization. Based on the results, we found that negative affectivity was positively related to perceived victimization. It means that employees with higher negative affectivity are more vulnerable to be the targets of victimization. They tend to put themselves as victims of aggressive actions by coworkers. High negative affectivity persons face emotional problems that affect their interaction with other people and place them to be potential targets of victimization. This result is consistent with a victim precipitation model and the findings of Aquino (1999).

We also found that obliging style in handling conflict had a negative effect on perceived victimization. When an individual exhibits an obliging style in handling conflict, he/she tends to avoid conflict. It may present him or herself as a submissive victim; that is, someone who perceived as weak, unassertive, and socially withdrawn (Aquino, 2000). In such a situation, individuals may become a target of victimization.

This study revealed a positive association between the dominating style and perceived victimization. The more an individual show is dominating style when conflicts with others, he/she will become a more vulnerable target of aggressive acts. It is believed that dominating is ineffective and can lead to a conflict of social interaction (Lee, 2008). In line with hypothesis 4 , we detected that integrating style had a negative effect on perceived victimization. This finding underlined Aquino's study (2000) that found a significant relationship between integrating and perceived direct victimization.

\section{Conclusion}

This study has several important practical implications. An understanding of negative affectivity and conflict styles can contribute to the organization to prevent victimization in the environment. Managers in all levels should encourage some efforts in their workplace, such as developing emotional quotient and spiritual quotient programs for employees in order to minimize negative affectivity. In addition, leadership training for all managers is needed, especially to identify and avoid victimization situations among their staff. Also, it is important for the organization to have a certain mechanism to protect employees who might be a potential target of aggressive acts.

As in the case with most empirical research, this study has several limitations to be noted. First, because our study was conducted in the public sector, the generalizability of our results may also be limited. It will be interesting to investigate victimization across a variety of workplaces, so we can compare the results. Second, the use of self-report data reflected that data collecting was based on respondents' interpretation. It may increase the risk that respondents might interpret the questions in different ways. Future studies can take the use of more objective data or other source data into account. Third, this study did not analyze victimization from the perpetrator's perspective. Thus, the source of aggressive acts cannot be identified, whether coming from peers or supervisors. It would be useful to pay attention to both victims' and perpetrator's perspectives in the analysis. Finally, our study examined a specific form of victimization that was focused on individual determinants (negative affectivity and self-determination) and hierarchical status, we should note that it might not be generalized to other forms of victimization, such as abusive supervision (Harvey et al., 2007; Tepper et al., 2006), workplace aggression (Hepworth and Towler, 2004), and employee aggression (Greenber and Barling, 1999). Future research is encouraged to investigate the extent to which certain types of leaders, organizational factors, and person behaviors influence victimization.

\section{References}

Aquino, K., S.L.G. (200o), "Structural and individual determinants of workplace victimization: the effects of hierarchical status and conflict management style", Journal of Management, Vol. 26 No. 2, pp. 171-193.

Aquino, K., S.L.G. and K. Lamertz. (2004), “No Title”, Journal of Applied Psychology, Vol. 89 No. 6, pp. $1023-1034$.

Aquino, K., S.L.G., M. Bradfield and D.G. Allen. (1999), "The effects of negative affectivity, hierarchical status and selfdetermination on workplace victimization”, Academy of Management Journal, Vol. 42 No. 3, pp. 26o-272.

Baumeister, R.F., L. Smart and J. M. Boden. (1996), "No Title”, Psychological Review, Vol. 103, pp. 5-33.

Burke, M.J., Brief, A.P. and M. George. (1993), "The role of negative affectivity in understanding relations between selfreports of stressors and strains: A comment on the applied psychology literature., Journal of Applied Psychology, Vol. 78, pp. 402-412.

Felson, R.B. (1992), "'Kick 'em when they're down': Explanations of the relationship between stress and interpersonal aggression and violence”, Sociological Quarterly, Vol. 33, pp. 1-16.

Fox, S., P.E. Spector and D. Miles. (2001), "Counterproductive Work Behavior (CWB) in response to job stressors and 
organizational justice: Some mediator and moderator tests for autonomy and emotions", Journal of Vocational Behavior, Vol. 59, pp. 291-309.

Giacalone, R.. and Greenberg, J. (1997), Antisocial Behavior in Organizations, Sage, Thousand Oaks, CA.

Glomb, T.M. (2002), "Workplace anger and agression: Informing conceptual models with data from specific encounters., Journal of Occupational Health Psychology, Vol. 7, pp. 20-36.

Greenber, L. and J. Barling. (1999), "Predicting employee aggression against coworkers, subordinates and supervisors : the roles of person behaviors and perceived workplace factors”, Journal of Organizational Behavior, Vol. 20, pp. 897-913.

Harvey, P., J. Stoner, W. Hochwarter and C. Kacmar. (2007), “Coping with abusive supervision : The neutralizing efects of ingratiation and positive affect on negative employee outcomes”, The Leadership Quarterly, Vol. 18, pp. 264280.

Hauge, L.., Skokstad, A. and S. Enarsen. (2007), "Relationship between stressful work environments and bullying : Results of a large representative study", Work \& Stress, Vol. 21 No. 3, pp. 220-242.

Hepworth, W. and A. Towler. (2004), “The Effects of Individual Differences and Charismatic Leadership on Workplace Agression.", Journal of Occupational Health Psychology, Vol. 9 No. 2, pp. 176-185.

Lee, K.. (2008), "An Examination between The Relationships of Conflict Management Styles and Employees Satisfaction", International Journal of Business and Management, Vol. 3 No. 9, pp. 11-25

Tepper, B.J., Duffy, M.K., Henle, C.A. and L. S. Lambert. (2006), "Procedural Injustice, Victim Precipitation and Abusive Supervision", L. S. Lambert, Vol. 59, pp. 101-123.

Watson, D. and L. A. Clark. (1984), "Negative affectivity: The disposition to experience aversive emotional states", Psychological Bulletin, Vol. 96, pp. 465-490.

Wornham, D. (2003), "A Descriptive Investigation of Morality and Victimization at Work”, Journal of Business Ethics, Vol. 45, pp. 29-40. 